\title{
VENTRICULAR SEPTAL DEFECT WITH PULMONARY STENOSIS
}

\author{
BY \\ L. BROTMACHER AND MAURICE CAMPBELL \\ From the Cardiac Department, Guy's Hospital, and the Institute of Cardiology \\ Received October 21, 1957
}

\begin{abstract}
About one-tenth of our patients with an atrial or ventricular septal defect who have had cardiac catheterization had pulmonary stenosis as well. Wood (1956) found much the same. This proportion is probably higher than the true incidence, for patients with the double lesion are more likely to be catheterized, but the association is common enough to be of some practical importance from the point of view of diagnosis and surgical treatment. It is found much more commonly than would be expected by chance, though this is not surprising in the case of ventricular septal defects at least, for the two abnormalities always occur together in Fallot's tetralogy.

We are describing 15 acyanotic patients in whom a ventricular septal defect with a left-to-right shunt of moderate size was associated with pulmonary stenosis. These 15 had a systolic gradient between the right ventricle and the pulmonary trunk of between $35 \mathrm{~mm}$. and $100 \mathrm{~mm}$. $\mathrm{Hg}$. We think that $35 \mathrm{~mm}$. is about the level where there is likely to be an organic stenosis, and it was also the smallest systolic gradient that we have seen in a patient with proven pulmonary stenosis (by necropsy in Case 78). During the same period we have made a clinical diagnosis of uncomplicated ventricular septal defect in about 175 patients, of simple pulmonary stenosis in about 150, and of Fallot's tetralogy in about 700 . The true proportion of patients with Fallot's tetralogy is, however, much less than this for a large number of these have been sent to us specially for consideration of surgical treatment. We are also discussing briefly eight other patients with a gradient of between 15 and $31 \mathrm{~mm}$. between the right ventricle and the pulmonary artery. Sometimes, we think this is due to a Venturi effect, but its significance is discussed later.
\end{abstract}

\section{Clinical Features}

Diagnosis. Severe pulmonary stenosis and large ventricular septal defects are easy to diagnose when occurring alone, but lesser degrees may be difficult, especially if both lesions are present together. If radioscopy confirms a left-to-right shunt in such a patient, the diagnosis of ventricular septal defect alone may be accepted, as happened several times in our series. The double diagnosis was made clinically in only one of these patients (Case 74). This contrasts with cases of atrial septal defect with pulmonary stenosis where both were often recognized: presumably the rougher systolic murmur when the defect is ventricular makes the double diagnosis more difficult on auscultatory signs alone.

The diagnosis thought most likely at first was ventricular septal defect in seven (including one with pulmonary regurgitation), pulmonary stenosis in three, and both conditions in one patient. In the remaining four the presence of basal diastolic murmurs suggested the possibility of persistent ductus arteriosus alone or with a septal defect: necropsy confirmed that this was present as well as the other two conditions in Case 71; the long murmur in diastole was heard soon after the patient had recovered from subacute bacterial endocarditis and later disappeared in Case 67; and the cause of the murmur remains unknown in the other two. The diagnosis of ventricular septal defect and pulmonary stenosis was confirmed at operation in one and at necropsy in two patients. 
In retrospect, the combined diagnosis could have been made more often than it was, especially in those with moderately severe pulmonary stenosis. In patients with clinical and radiological evidence of ventricular septal defect and without auscultatory evidence of pulmonary hypertension, right ventricular preponderance in the electrocardiogram suggests the presence of associated pulmonary stenosis. Ten of the 15 patients showed right ventricular preponderance, two of these having $\mathrm{T}$ inversion in V1 and V2 and four others in V1 only; three probably had some right preponderance, but two did not have any evidence of this. There may be evidence of some hypertrophy of both ventricles in many cases of ventricular septal defect, but right ventricular preponderance is uncommon unless there is fairly severe pulmonary hypertension (Mannheimer et al., 1957).

Symptoms and General Features. These 15 patients do not seem to form a homogeneous group, and though apart from our notes we have a clear picture of ten of them, it is not easy to make many generalizations. They were clinically acyanotic when they were first seen, and as a rule not greatly disabled. Our oldest patient is, however, only 25 years old. In spite of this, we think that for two patients with ventricular septal defects of the same size, the outlook is better for the one with moderate pulmonary stenosis in addition; since the evidence of this tending to become more severe is inconclusive, whereas the pulmonary arteriolar resistance associated with large shunts tends to rise (Brotmacher and Campbell, 1958).

All 15 patients were clinically acyanotic at rest when the diagnosis was first made, but even then there was a small right-to-left shunt in two (Cases 66 and 77). One became cyanotic on exercise and two others may have done so (Cases 73, 76, and 79). Three of the four who were recatheterized from two to seven years later had this done because they had become cyanotic: in two the arterial oxygen saturation at rest had fallen (Cases 74 and 80) and in the third it fell on exertion (Case 67). Another patient was always acyanotic when she was 3 but became cyanotic on exertion when she was 7 years old (Case 71). This means that of the 15 patients, 2 were slightly cyanotic at rest and 5 others became so after exercise by the time they last attended hospital.

Squatting was recorded in one patient only when he was first seen: he may have become cyanotic on exertion, for two years later he had become so, even at rest (Case 74). Two others started squatting later as they became cyanotic (Cases 67 and 71). Three had severe kyphoscoliosis and in one of these it was an important part of her disability (Case 77).

The size of the heart was variable, the enlargement being slight (c.t.r. 50-54\%) in five, moderate (c.t.r. $55-59 \%$ ) in five, and great (c.t.r. over $60 \%$ ) in five cases-not very different from our findings in uncomplicated ventricular septal defect. Those with only slight enlargement had the smaller shunts, an average of 2.4 against 4.4 litres a minute in the others, but there was so much overlapping that this is unlikely to be the whole explanation of the differences in the size of the heart. Both ventricles usually seemed to be enlarged but this often happens with ventricular septal defect alone. The aortic arch was left-sided in 14 patients, but right-sided in the fifteenth.

Patients who have Died. Two of these patients have died, one after an attempt to close her ventricular septal defect and one with other congenital abnormalities and congestive heart failure. Short case reports follow.

Case 71. A girl, aged 3 when she was first seen, was acyanotic and had a very large heart: she was thought to have a septal defect. Later she became more disabled and cyanotic on exertion, and started squatting: a continuous murmur was then heard and a persistent ductus suspected. When she was 6 , catheterization showed pulmonary stenosis and confirmed a left-to-right shunt, and the catheter passed from the right ventricle to the aorta. As she was becoming worse, the co-existing ductus was closed and an attempt was made to close her ventricular septal defect, but unfortunately she died.

At necropsy the heart was greatly enlarged and there was nothing to distinguish it from a heart with Fallot's tetralogy and a persistent ductus that had been successfully closed. The attempts to close the ventricular septal defect, which was at the usual high site but unusually difficult to approach, and to relieve the infundibular stenosis had not been successful but prevented study of the original anatomy. There were no other congenital abnormalities.

Case 78. A boy, aged 16, did not play games, but complained of little and cycled up to 50 miles in a day. He was acyanotic but had an enormous heart (c.t.r. $78 \%$ ). Catheterization demonstrated a left-to- 
right shunt of 8.2 litres a minute and an infundibular stenosis with a gradient of $35 \mathrm{~mm}$. $\mathrm{Hg}$. When 19 he came into hospital again, this time with congestive heart failure, from which he died.

At necropsy the heart weighed $980 \mathrm{~g}$.- a size that was not easily explained by the lesions that were found, but the coronary arteries were very small. There was a ventricular septal defect, $2.5 \mathrm{~cm}$. across, at the usual site. There was infundibular stenosis with an opening $1.5 \mathrm{~cm}$. in diameter and a large infundibular chamber. The pulmonary valve was bicuspid but not stenosed. The aorta seemed to over-ride the ventricular septal defect and was small. At the level of the ligamentum arteriosum it became smaller but unlike an ordinary coarctation, it was also hypoplastic beyond this; there was general medio-necrosis cystica of the aorta and pulmonary artery. There were many congenital abnormalities outside the heart, the most striking being an additional bronchus to the right upper lobe, two left renal arteries, but an absence of the right adrenal gland and right kidney and ureter. This case will be reported fully by Baylis.

\section{HÆMODYNAMIC FINDINGS}

The diagnosis was proved at cardiac catheterization and the pulmonary artery was intubated in every patient. The aorta was entered from the right ventricle in four. In all there was proof of a left-to-right shunt, but the shunts were small for cases of ventricular septal defect, averaging $3 \cdot 2$ litres a minute. There was no tendency for the shunts to change in size with age or, with the exception of Case 78, to depend on the size of the pulmonary gradient. This exception was the boy who died, who had the lowest gradient of $35 \mathrm{~mm}$. and the largest shunt, 8.2 litres: he was the only patient where it was more than $5 \cdot 2$ litres a minute. The data are given in Table I.

TABLE I

Hæmodynamic Data in Patients with Ventricular Septal Defect and Pulmonary Stenosis

\begin{tabular}{|c|c|c|c|c|c|c|c|c|c|c|c|}
\hline \multirow{3}{*}{$\begin{array}{l}\text { Case } \\
\text { No. }\end{array}$} & \multirow{3}{*}{$\begin{array}{l}\text { Sex } \\
\text { and } \\
\text { age }\end{array}$} & \multirow{3}{*}{$\begin{array}{l}\text { Surface } \\
\text { area } \\
\text { (sq. m.) }\end{array}$} & \multirow{3}{*}{$\begin{array}{c}\text { Systemic } \\
\text { flow } \\
\text { (1./min.) }\end{array}$} & \multirow{3}{*}{$\begin{array}{l}\text { Pulm. } \\
\text { flow } \\
\text { (1./min.) }\end{array}$} & \multirow{3}{*}{$\begin{array}{c}\text { Art. } \\
\mathrm{O}_{2} \\
\text { sat. }\end{array}$} & \multicolumn{6}{|c|}{ Pressures (mm. Hg) } \\
\hline & & & & & & \multirow{2}{*}{ Systemic } & \multicolumn{2}{|c|}{ Right ventricle } & \multicolumn{2}{|c|}{ Pulmonary artery } & \multirow{2}{*}{$\begin{array}{l}\text { Pulm. } \\
\text { cap. } \\
\text { (mean) }\end{array}$} \\
\hline & & & & & & & Body & $\begin{array}{c}\text { Infundi- } \\
\text { bulum } \\
\text { (if lower) }\end{array}$ & Phasic & Mean & \\
\hline $66^{*}$ & M5 & 0.91 & $2 \cdot 92$ & $6 \cdot 12$ & 93 & $110 / 75^{3}$ & $74 / 0$ & $37 / 0$ & $36 / 16$ & 25 & - \\
\hline $67 *$ & M6 & 0.68 & $2 \cdot 2$ & $3 \cdot 7$ & 95 & $110 / 75^{3}$ & $89 / 4$ & - & $35-57 / 8-21$ & - & \\
\hline $67^{*}$ & M13 & 1.09 & $5 \cdot 2$ & $6 \cdot 0$ & 95 & $95 / 65$ & $89 / 2$ & $19 / 3$ & $13 / 4$ & - & 3 \\
\hline 68 & F7 & 0.86 & $4 \cdot 0$ & $9 \cdot 2$ & 99 & $150 / 110 \dagger$ & $98 / 1$ & $42 / 9$ & $48 / 33$ & 41 & 12 \\
\hline 69 & F7 & 1.00 & $5 \cdot 2$ & $6 \cdot \overline{2}$ & 95 & $90 / 34$ & $88 / 0$ & $22 / 2$ & $23 / 10$ & 14 & 6 \\
\hline 70 & F7 & $0 \cdot 70$ & $8 \cdot 9$ & $14 \cdot 1$ & 96 & $76 / 52$ & $64 / 3$ & $31 / 7$ & $26 / 9$ & 16 & 8 \\
\hline 71 & F7 & $0 \cdot 84$ & $2 \cdot 9$ & $5 \cdot 3$ & 97 & $88 / 55$ & $86 / 8$ & $30 / 8$ & $21 / 9$ & 14 & 12 \\
\hline 72 & F9 & $1 \cdot 00$ & $3 \cdot 0$ & $6 \cdot 0$ & 95 & $120 / 80^{3}$ & $92 / 6$ & - & $19 / 14$ & 17 & 13 \\
\hline \multirow{2}{*}{73} & F5 & 0.65 & - & - & 94 & $105 / 75^{3}$ & $114 / 9$ & - & - & 一 & - \\
\hline & F11 & $1 \cdot 10$ & $6 \cdot 8$ & $11 \cdot 2$ & 95 & $110 / 85^{3}$ & $110 / 5$ & $13 / 8$ & $16 / 4$ & 11 & 7 \\
\hline 74 & M10 & $1 \cdot 26$ & - & - & 98 & $120 / 75$ & $100 / 0$ & $\overline{0}$ & - & - & - \\
\hline 75 & $\begin{array}{l}\text { M12 } \\
\text { F13 }\end{array}$ & $\begin{array}{l}1.50 \\
1.42\end{array}$ & $\begin{array}{l}3 \cdot 5^{1} \\
7 \cdot 1\end{array}$ & $\begin{array}{c}5 \cdot 1^{11} \\
10 \cdot 6\end{array}$ & $\begin{array}{l}89 \\
95\end{array}$ & $\begin{array}{l}130 / 85 \\
104 / 70\end{array}$ & $\begin{array}{r}95 / 9 \\
104 / 2\end{array}$ & $\begin{array}{l}28 / 6 \\
37 / 2\end{array}$ & $\begin{array}{l}15 / 3 \\
16 / 4\end{array}$ & $\begin{array}{l}8 \\
7\end{array}$ & $\begin{array}{l}0 \\
3\end{array}$ \\
\hline $76^{*}$ & M14 & $1 \cdot 11$ & $4 \cdot 9$ & $8 \cdot 1$ & 95 & $125 / 81$ & $110 / 0$ & - & $23 / 8$ & 11 & - \\
\hline 77 & F15 & - & $2 \cdot 6^{2}$ & $5 \cdot 2^{2}$ & 91 & $115 / 80$ & $78 / 0$ & - & $18 / 9$ & 13 & 9 \\
\hline $78^{*}$ & M17 & $1 \cdot 37$ & $4 \cdot 5$ & $12 \cdot 7$ & 97 & $106 / 61$ & $85 / 2$ & $51 / 4$ & $50 / 15$ & 30 & - \\
\hline $79^{*}$ & F19 & $1 \cdot 56$ & $5 \cdot 4$ & $9 \cdot 5$ & 95 & $102 / 72$ & $98 / 5$ & -10 & $30 / 7$ & 24 & 一 \\
\hline \multirow{2}{*}{$80^{*}$} & M25 & $1 \cdot 75$ & $4 \cdot 4$ & $6 \cdot 5$ & 94 & $102 / 67$ & $121 / 3$ & $31 / 2$ & $22 / 10$ & 16 & 一 \\
\hline & M26 & $1 \cdot 73$ & $4 \cdot 5$ & $6 \cdot 4$ & 90 & $120 / 80^{3}$ & $104 / 15$ & $39 / 8$ & $27 / 12$ & 19 & \\
\hline
\end{tabular}

1 Veno-arterial shunt of $0.71 . / \mathrm{min}$. present. 2 Veno-arterial shunt possibly present.

3 Not measured during cardiac catheterization. † Generally 110/70.

* These six were included in Table IX by Campbell (1954) as Cases B1-5 and E2.

Excluding patients with a high pulmonary arteriolar resistance that had reduced the shunt, Brotmacher and Campbell (1958) found that the average left-to-right shunt in uncomplicated 
ventricular septal defect was 8.8 litres a minute, so that in the present 15 patients it was comparatively small. In fact, pulmonary stenosis reduced the average shunt to about the same level as did a pulmonary arteriolar resistance of between 6 and 12 units (3.2 and $3 \cdot 5$ litres a minute respectively).

In three patients the oxygen content of the pulmonary arterial blood was more than $1.0 \mathrm{ml}$. per $100 \mathrm{ml}$. above that of the right ventricle, suggesting that part of the shunt was directly into the pulmonary artery. In none of these three was there any clinical evidence to suggest a persistent ductus, and in one it was excluded at necropsy. No pulmonary arterial sample was obtained in the patient in whom the presence of a persistent ductus was confirmed at necropsy.

The systolic gradient between the right ventricle and the pulmonary trunk was between 35 and $52 \mathrm{~mm}$. in five and between 60 and $99 \mathrm{~mm}$. in eleven patients, counting Case 67 twice since the gradient had risen from 43 to $76 \mathrm{~mm}$. during seven years. The site of the gradient was demonstrated in thirteen patients-at infundibular level in nine (four of whom had gradients of less than $10 \mathrm{~mm}$. at valve level also), at valve level in two, and at both levels, though mainly infundibular, in two (Cases 74 and 75). This distribution might be found in a group with Fallot's tetralogy though generally there would be more at the valve level and more at both levels. It contrasts sharply with cases of atrial septal defect and pulmonary stenosis where it is nearly always at valve level.

The systolic pressure in the right ventricle was high in all these 15 patients, and was within $20 \mathrm{~mm}$. of the systemic level in all but five of them. The pulmonary arterial systolic pressure was moderately increased in two (48 and $50 \mathrm{~mm}$., Cases 68 and 78), slightly above normal in two (in one of whom it had fallen to normal seven years later, Case 67), and normal in the remainder. In those where the pressure was raised, the stenosis cannot have obstructed the pulmonary flow greatly, but presumably the pressure would have been still higher if there had been no stenosis. The pulmonary arterial tracings showed well-defined pulsations, whereas in Fallot's tetralogy it is not often possible to record much more than a mean pressure. The pulmonary arterial samples were less saturated than the ventricular in two patients only, though this is common in Fallot's tetralogy when the catheter obstructs appreciably the flow through the stenosis. The mean pulmonary capillary venous pressure was $8 \mathrm{~mm}$., which is $1 \mathrm{~mm}$. less than the mean of the patients with a ventricular septal defect and a normal pulmonary arterial pressure.

Recatheterization after an Interval. Catheterization was repeated in four patients but in two it had not been possible to enter the pulmonary artery on the first occasions. In both these the systolic pressure in the right ventricle was about the same, and not much below the systemic (Cases 73 and 74).

In Case 80 the interval was only two years because he had become slightly cyanosed and was able to do rather less: the findings were hardly changed except that the arterial oxygen saturation had fallen from 94 to 90 per cent. It had fallen in one other (Case 74, 98 to $89 \%$ ) but was unchanged in two (Cases 67 and 73). Case 67, however, was always acyanotic when 6, but when 13 became cyanotic on exertion and this was confirmed during the second catheterization (art. $\mathrm{O}_{2}$ sat. 95 to $90 \%$ with exercise). The right ventricular pressure was unchanged $(89 / 2-4)$ but the pulmonary arterial pressure which had been variable earlier $(57 / 21$ and $35 / 8)$ was now lower. The left-to-right shunt was reduced and, relatively, greatly reduced, from $2 \cdot 1$ to 0.7 litres $/ \mathrm{sq} . \mathrm{m} . / \mathrm{min}$.

\section{Patients With SMaller Gradients}

We are discussing more briefly 8 patients who had a ventricular septal defect with a left-to-right shunt and a systolic gradient between the right ventricle and pulmonary trunk of from 16 to $31 \mathrm{~mm}$. (see Table II). The gradient was demonstrated on a withdrawal tracing in 5 of these 8 , and was at infundibular level in two and at valve level in three. In two the catheter passed through the defect to the left ventricle, which is unusual with cases of ventricular septal defect.

In three of them there was some evidence against the presence of any organic stenosis. In one, with a gradient of $20 \mathrm{~mm}$., no obstruction could be demonstrated at necropsy (Case 1, Baylis 
et al., 1955), although a functional infundibular stenosis may have been present in life (Case 60). In the second, with a gradient of $16 \mathrm{~mm}$., a loop of catheter could be passed into the pulmonary artery (Case 59). These two had very large hearts and aortic regurgitation and both had pulmonary flows of over 14 litres a minute, and the gradient recorded may have been due to a Venturi effect. In the third, changing conditions may explain the gradient of $18 \mathrm{~mm}$. for the recorded infundibular pressure was higher than that recorded in the body of the right ventricle (Case 65).

In the remaining five, it is more difficult to decide whether they had a small organic stenosis or not. In two the gradients ( 16 and $18 \mathrm{~mm}$.) were no larger than in those just described but in the other three they were between 23 and $31 \mathrm{~mm}$. Two had a large pulmonary flow and the pulmonary arterial systolic complexes were notched, suggesting that here too the pulmonary pressure as recorded was reduced as the result of a Venturi effect. There may, however, have been a slight stenosis in some of them, and the possibility of this is greater where the pulmonary flow was only moderately raised; or the obstruction may have been relative, a normal-sized valve ring intervening between a dilated outflow tract and a dilated pulmonary trunk.

TABLE II

Hemodynamic Data in Patients with Ventricular Septal Defect and a Small Right Ventricular to Pulmonary Artery Pressure Gradient

\begin{tabular}{|c|c|c|c|c|c|c|c|c|c|c|}
\hline \multirow{3}{*}{$\begin{array}{l}\text { Case } \\
\text { No. }\end{array}$} & \multirow{3}{*}{$\begin{array}{c}\text { Sex and } \\
\text { age }\end{array}$} & \multirow{3}{*}{$\begin{array}{c}\text { Surface } \\
\text { area } \\
\text { (sq. m.) }\end{array}$} & \multirow{3}{*}{$\begin{array}{l}\text { Systemic } \\
\text { flow } \\
\text { (1./min.) }\end{array}$} & \multirow{3}{*}{$\begin{array}{c}\text { Pulm. } \\
\text { flow } \\
\text { (1./min.) }\end{array}$} & \multicolumn{6}{|c|}{ Pressures $(\mathrm{mm} . \mathrm{Hg})$} \\
\hline & & & & & \multirow[t]{2}{*}{ Systemic } & \multicolumn{2}{|c|}{ R. V. } & \multicolumn{2}{|c|}{ P. A. } & \multirow{2}{*}{$\begin{array}{l}\text { Pulm. } \\
\text { cap. } \\
\text { (mean) }\end{array}$} \\
\hline & & & & & & Body & $\begin{array}{l}\text { Infundi- } \\
\text { bulum }\end{array}$ & Phasic & Mean & \\
\hline $\begin{array}{l}58 \\
59 \\
60 \\
61 \\
62\end{array}$ & $\begin{array}{l}\text { F4 } \\
\text { M7 } \\
\text { M9 } \\
\text { M10 } \\
\text { F11 }\end{array}$ & $\begin{array}{l}0.62 \\
0.84 \\
0.94 \\
1.08 \\
-\end{array}$ & $\begin{array}{c}3 \cdot 2 \\
4 \cdot 1 \\
4 \cdot 5 \\
4 \cdot 31 \\
\text { Left-to-ri } \\
\text { pres }\end{array}$ & $\begin{array}{c}10 \cdot 2 \\
14 \cdot 4 \\
14 \cdot 2 \\
8 \cdot 71 \\
\text { hht shunt } \\
\text { ent }\end{array}$ & $\begin{array}{c}129 / 76 \\
100 / 50^{2} \\
140 / 50 \\
80 / 50 \\
110 / 70\end{array}$ & $\begin{array}{l}62 / 14 \\
53 / 5 \\
75 / 0 \\
76 / 9 \\
43 / 8\end{array}$ & $\begin{array}{l}\overline{-} \\
\overline{55 / 2} \\
-\end{array}$ & $\begin{array}{l}46 / 18 \\
37 / 20 \\
55 / 25 \\
58 / 32 \\
18 / 10\end{array}$ & $\begin{array}{l}232) \\
227) \\
(35) \\
(42) \\
(13)\end{array}$ & $\begin{array}{l}15 \\
= \\
=\end{array}$ \\
\hline $\begin{array}{l}63 \\
64\end{array}$ & $\begin{array}{l}\text { F12 } \\
\text { F18 }\end{array}$ & $\begin{array}{l}1.67 \\
1.62\end{array}$ & $\begin{array}{l}9.4 \\
4.5\end{array}$ & $\begin{array}{l}15 \cdot 4 \\
21 \cdot 2\end{array}$ & $\begin{array}{c}126 / 71 \\
85 / 4 \\
\text { (L.V.) }\end{array}$ & $\begin{array}{l}47 / 9 \\
42 / 0\end{array}$ & - & $\begin{array}{l}24 / 9 \\
11 / 2\end{array}$ & $\begin{array}{r}(16) \\
(6)\end{array}$ & $\begin{array}{r}12 \\
3\end{array}$ \\
\hline 65 & F19 & 1.52 & $3 \cdot 5$ & $8 \cdot 2$ & $130 / 70$ & $29 /-1$ & $38 / 6$ & $20 / 5$ & (12) & 4 \\
\hline
\end{tabular}

1 Veno-arterial shunt of $0.51 . / \mathrm{min}$. also present.

2 Not measured during cardiac catheterization.

All these patients were under 20 and most were under 12 years of age. They appeared to be ordinary cases of ventricular septal defect, and this was the clinical diagnosis made in all, though the combined lesion had been suspected in one. The shunts were larger than in the 15 patients with more severe stenosis discussed earlier. They averaged 8.4 litres, and were over 6.0 litres a minute in all but two, so that on the average 63 per cent of the blood from the left ventricle (instead of 40 per cent in those with gradients of from $35-99 \mathrm{~mm}$.) passed to the right ventricle and back to the lungs. The pulmonary artery is, of course, slightly protected from the high pressure that might result from this but the right ventricle is not.

In four patients (Cases 62-65) the right ventricular systolic pressure was only moderately raised (under $50 \mathrm{~mm}$.) and the pulmonary arterial pressure was normal. These four seem somewhere between acyanotic Fallot's tetralogy and ventricular septal defect with a normal pulmonary pressure. In the remaining four, the right ventricular pressure was rather higher (53-76 mm.) and despite the gradient the pulmonary arterial pressure also was raised $(37-58 \mathrm{~mm}$.); they are, therefore, more like the type of ventricular septal defect that is associated with pulmonary hypertension, and this is emphasized by the demonstration of a small veno-arterial shunt in one of them (Case 61).

The boundaries of these groups have necessarily been drawn somewhat arbitrarily. The patient 
with a gradient of $35 \mathrm{~mm}$. was proved to have infundibular stenosis at necropsy, and all those with gradients larger than this have been counted as having organic pulmonary stenosis. The patients with gradients below $35 \mathrm{~mm}$. have been assumed to have no significant pulmonary stenosis, and were included among those with uncomplicated ventricular septal defect in the clinical part of our previous paper (Brotmacher and Campbell, 1958) but not in the section on hæmodynamic findings, because the relationship of changes in the pulmonary pressure with age would be disturbed when there was a gradient between the right ventricle and the pulmonary artery.

\section{The LeVels at which Systolic Gradients are Significant of Stenosis}

Mitral stenosis and persistent ductus arteriosus are hardly ever associated with organic pulmonary stenosis, and there is no increased flow through the pulmonary valve that can play any part in producing a gradient: these groups give a picture, therefore, of the apparent gradient that may be found, e.g. from technical errors and varying conditions during the catheterization. Gradients of $12 \mathrm{~mm}$. have been found in patients with mitral stenosis where pulmonary stenosis could reasonably be excluded.

Among 70 cases of persistent ductus that had been catheterized, excluding two with severe proven pulmonary stenosis, there were only four where the systolic gradient across the pulmonary valve was more than $5 \mathrm{~mm}$., and in all these it was between 10 and $16 \mathrm{~mm}$. Two at least of these had withdrawal tracings that seemed technically reliable. In none was there any supporting evidence of pulmonary stenosis, and when there had been a systolic murmur that might have been due to pulmonary stenosis it disappeared after the ductus had been closed. Gradients of $16 \mathrm{~mm}$. or less may, therefore, be due to changing conditions and other factors and provide no reliable evidence of stenosis.

When we come to septal defects, a new factor has to be considered for the flow through the pulmonary valve is increased, sometimes greatly so. At the aortic valve-with a normal flow-the orifice must be reduced to about a third of the usual size before a gradient across it develops (Gorlin et al., 1955). With a normal flow this is probably equally true at the pulmonary valve: a slight organic stenosis or even a relative stenosis due to a normal-sized valve ring interposed between a dilated outflow tract and a dilated pulmonary trunk may, however, produce a gradient when the flow is increased-a gradient that would be abolished if the pulmonary flow were reduced by successful closure of the defect, even if the stenosis were unrelieved. Gradients between the right ventricle and the pulmonary trunk cannot be explained as due to the large flow entirely, for they are not found with many of the larger pulmonary flows and may be found with flows that are only moderately increased. The application of these factors to our findings in eight patients with a ventricular septal defect and a small gradient between 15 and $31 \mathrm{~mm}$. has been discussed (p. 382).

When considering similar patients with atrial septal defect, a level of $20 \mathrm{~mm}$. was taken as the best dividing line between a systolic gradient that was significant of pulmonary stenosis and one that was not (Campbell et al., 1957) for over this level there was generally some supporting evidence, such as a loud murmur, sometimes with a thrill Since then we have seen a boy aged 12 who, after many consultations, was sent to us for operation with a diagnosis of pulmonary stenosis alone: we too thought this was more important than his left-to-right shunt but, in fact, the latter was 11.6 litres a minute and at atrial level, and the pulmonary gradient was no more than $20 \mathrm{~mm}$. When the atrial septal defect had been closed, the murmur that had led to the diagnosis of pulmonary stenosis disappeared. Gradients larger than this may be abolished after successful closure of the defect, showing that there is no stenosis that is significant with a normal flow.

We have now seen 16 cases of atrial septal defect with a gradient between 20 and $100 \mathrm{~mm}$. It was relatively small, between 20 and $42 \mathrm{~mm}$., in 10 of these 16 , and probably there was little or no stenosis as the shunts were large and averaged 8.4 litres a minute. In one of these, a girl aged 14, the systolic gradient had increased from 29 to $46 \mathrm{~mm}$. in five years with little change in the size of the shunt, but some at least of this was due to a Venturi effect. In the other 6, the gradient was much larger, between 70 and $90 \mathrm{~mm}$.: in three of them the shunts were equally large so we are left 
uncertain about organic stenosis, but in the other three it was almost certainly severe as the shunts were quite small.

Among other patients who have been catheterized, $12-16 \cdot \mathrm{mm}$. are the smallest gradients encountered where we think that other evidence supports some organic stenosis, even though it must be slight. A boy, aged 11, who was carefully observed by several physicians and was without symptoms or cardiac enlargement, was diagnosed as having a small ventricular septal defect, but at catheterization the only lesion found was infundibular stenosis with a gradient of $12 \mathrm{~mm}$. A man, aged 20, with coarctation was catheterized because he had such a striking pulmonary systolic murmur and thrill, but the gradient was only $12 \mathrm{~mm}$.: the signs persisted after a successful operation for coarctation. A woman, aged 41, has been under personal observation for 30 years with a diagnosis of pulmonary stenosis: catheterization revealed that she had an atrial septal defect with a left-to-right shunt of 3.5 litres a minute and a gradient across the pulmonary valve that was only $16 \mathrm{~mm}$.

Summary. Our general conclusions are, therefore, that no certain significance can be attached to gradients of less than $16 \mathrm{~mm}$. for they may be due to changing conditions or other technical causes. Sometimes, however, when the flow is not increased, gradients of from 12 to $20 \mathrm{~mm}$. may be significant of organic stenosis, provided that the diagnosis is supported by other reliable signs and does not rest on the pressure tracings alone. A gradient larger than this is less likely to be due to outside causes; but if the pulmonary flow is increased, it must be of the order of 35 or perhaps $45 \mathrm{~mm}$. before one can be reasonably sure that there is organic stenosis.

The Site of the Gradient. In atrial septal defect the gradient was always at valve level, except in one case where it was infundibular and in one where it was at both levels. With ventricular septal defects, however, the level was at the valve in 5, at the infundibulum in 11, and at both levels in 2 cases. This difference supports the view that sometimes even a small gradient has a real anatomical cause and is not due solely to the increased flow.

\section{DisCUSSION}

Patients with pulmonary stenosis and a ventricular septal defect with a left-to-right shunt have been reported by several authors. Wood et al. (1954), reporting on 60 patients with ventricular septal defect, discussed shortly 11 others who had, in addition, some degree of pulmonary stenosis, 6 clinically ventricular septal defect with stenosis that was only slight and 5 clinically pulmonary stenosis that was moderate or severe. Eldridge and Hultgren (1955) reported four, and Bashour and Winchell (1955) three patients. Contro and Brostoff (1955) reported eight with gradients across the pulmonary valve of between 45 and $85 \mathrm{~mm}$.: all were acyanotic at rest but two became cyanotic with easy exercise. Seven patients were studied in considerable detail by Callahan et al. (1955): four of them had atrial'septal defects also. In a later paper, Bashour et al. (1957) reported eight patients between 17 and 53 years of age, with right ventricular pressures between 70 and $138 \mathrm{~mm}$. and left-to-right shunts between 1.3 and 6.9 litres a minute: they were able to lead reasonably normal lives, but the oldest had become cyanotic at rest and four became cyanotic on exertion.

\section{Relationship to Fallot's Tetralogy}

This relationship is certainly a close one for patients with pulmonary stenosis and a ventricular septal defect always have two of the four features that characterize Fallot's tetralogy. If the stenosis is moderately severe they have also the third feature of right ventricular hypertrophy, which in any case is a secondary result and not a primary abnormality. We do not know whether the acyanotic patients have or have not the fourth feature-the over-riding aorta.

Significance of Aortic Over-riding. Varying degrees of this occur and the degree of over-riding may be secondary to the right-to-left shunt rather than primary. As we have pointed out (Brotmacher and Campbell, 1958), unless there is transposition, the presence or absence of a rightto-left shunt does not depend on this but on the relative pulmonary and systemic resistances. This is equally true whether the obstruction to blood flow through the lungs is offered by increased 
pulmonary arteriolar resistance or by pulmonary stenosis. In our two cases with necropsies (Cases 71 and 78) there was nothing in the relationship between the aortic root and the ventricular septal defect to distinguish them from cases of classical Fallot's tetralogy, although Case 78 was still acyanotic when he died at the age of 19.

That over-riding of the aorta may be present without cyanosis is proved by the condition of many patients with Fallot's tetralogy who have had an unusually successful operation, generally a valvotomy or infundibular resection, and have become good examples of acyanotic Fallot's tetralogy. Campbell et al. (1954) discussed some of these who had been recatheterized after operation and five of those recorded in their Table VI were acyanotic, with an arterial oxygen saturation between 92 and 98 per cent, although it had averaged as low as 81 per cent before operation. The pulmonary flow was now larger than the systemic flow, the average proportion being 3 to 2 , although before operation it had been 1 to 2 ; the right ventricular pressure was hardly changed and the degree of over-riding of the aorta was, of course, the same. Only in one girl had the pulmonary pressure risen above normal (from $14 / 7$ to $38 / 12$ ). She has remained very well clinically for seven years and is an excellent example of acyanotic Fallot's tetraology. Wood also (1956) has seen several cases of this type.

Development of Cyanosis. The patients who had had successful operations are certain examples of acyanotic Fallot's tetralogy. Are there others who may justly be described as such? Generally in Fallot's tetralogy cyanosis becomes noticeable in infancy, in our experience before eighteen months, though exceptionally it may be much later. One deeply-cyanosed man, aged 29 when he died, had so little disability or cyanosis until three years before his death, that he was thought to have pulmonary stenosis with a closed ventricular septum rather than Fallot's tetralogy, which was, however, demonstrated at necropsy. We have seen a few other patients where cyanosis has not been noted for several years after birth. Brown (1950, p. 196) says it is exceptional but mentions one such man where the diagnosis was established at necropsy when he died at the age of 29 . Wood (1956), however, says that 15 per cent of his patients with Fallot's tetralogy had not developed cyanosis at rest when they were seen. Wood et al. (1954) discussed 10 cases described as acyanotic Fallot's tetralogy but the distinction between these and others described as cases of ventricular septal defect and pulmonary stenosis is not clear.

Admittedly some patients with Fallot's tetralogy have much less cyanosis than others and sometimes it may be slight except on exertion. It is, therefore, possible but unlikely that one may see some cases of classical Fallot's tetralogy in an apparently pre-cyanotic stage. When our 15 cases with pulmonary stenosis and a ventricular septal defect were first seem, two only had also a small right-to-left shunt at rest and three probably became slightly cyanotic on exertion, but all were clinically acyanotic and the shunt was entirely or mainly left-to-right. During the time they were under observation (up to seven years) two became slightly cyanotic at rest and two more became cyanotic on exertion, so that they were more difficult to distinguish from classical Fallot's tetralogy. A longer follow-up is therefore needed to know if the others will do this, but we think that most of them would have done so earlier and more completely if they were going to do so at all, for they still had a moderate left-to-right shunt which would have to be abolished or greatly reduced. A large left-to-right shunt is not found with classical Fallot's tetralogy: a small one can sometimes be demonstrated (Holling, 1952) but in our experience, when it is present, it is generally less than one litre a minute.

Whether the condition from which our patients are suffering is termed ventricular septal defect with pulmonary stenosis or acyanotic Fallot's tetralogy is, therefore, mainly a matter of nomenclature. One cannot say that the latter term is inaccurate, but there is not much object in it unless central cyanosis is going to develop later, because this is such a cardinal feature of Fallot's tetralogy. As we have shown, cyanosis at rest develops only in a minority and it is not possible to predict which patients will develop this: further, many are still without cyanosis on exertion. Partly because of this and partly because most of our patients still have a moderate left-to-right shunt we think it better to describe the condition as ventricular septal defect with pulmonary stenosis. 


\section{Surgical Treatment}

The left-to-right shunts in our 15 acyanotic patients were only moderate, averaging 3.2 litres and being 5.2 litres a minute or less in all but one. This shows that in these patients pulmonary stenosis has advantages as well as drawbacks. We think that pulmonary valvotomy or infundibular resection is contra-indicated unless the ventricular septal defect can be closed at the same time, even when the stenosis is severe enough to produce a right ventricular systolic pressure approaching the systemic. The patient would presumably have a large instead of a moderate-sized shunt, and would then be likely to develop an increased pulmonary arteriolar resistance that would probably rise over the years and again expose him to the risk of developing a right-to-left shunt, for which nothing could be done.

These considerations apply even more strongly to patients who are acyanotic with exercise and to those in whom the gradient is small, for sometimes the pulmonary arterial pressure is raised in spite of the stenosis. Contro and Brostoff (1955) agree that valvotomy alone should not be carried out in patients with pulmonary stenosis and a left-to-right shunt through a ventricular septal defect. Bashour et al. (1957) think that the prognosis is too good to justify the risks of surgical treatment. Possibly, however, operation may be the best course at present available if the right ventricular pressure becomes high enough to produce a right-to-left shunt of considerable size even at rest.

We have referred to some of our patients with Fallot's tetralogy where the cyanosis was trivial except on exertion. At first, when considering surgical treatment for them, we were hesitant about advising it, for there is some correlation between the degrees of cyanosis and of disability though not a very close one. We remember particularly two patients who were very disabled but hardly cyanotic until they exerted themselves: when an anastomotic operation had been carried out they did in fact benefit as much as most others and have maintained their improvement, although the right-to-left shunt must have been small at rest. We have, however, no reason to think that these patients had appreciable left-to-right shunts before operation, and they became very cyanotic on exertion.

When there is a significant left-to-right shunt, pulmonary valvotomy is contra-indicated until the ventricular septal defect can be closed with relative safety.

\section{SUMMARY AND CONCLUSIONS}

We are reporting 15 patients who had a ventricular septal defect with a left-to-right shunt and pulmonary stenosis in addition. Initially all these were clinically acyanotic and all had a left-toright shunt, although two had also a small right-to-left shunt and three probably became cyanotic on exertion. During subsequent years two have become slightly cyanotic, even at rest.

The diagnosis in most of them was ventricular septal defect because of the hæmodynamic effects of the left-to-right shunt, but sometimes pulmonary stenosis and rarely both lesions were suspected. In retrospect, the degree of right venticular preponderance electrocardiographically, in the absence of clinical pulmonary hypertension, should have led to the combined diagnosis more often.

Generally, the disability of these patients was not great, though often they had a large heart. A history of squatting was unusual.

Patients with Fallot's tetralogy rarely have a left-to-right shunt that exceeds one litre a minute and generally have a right-to-left shunt large enough to make them obviously cyanotic even at rest. Nevertheless, the dividing line between this condition and Fallot's tetralogy is rather narrow. Our patients were chosen on the diagnosis made after catheterization rather than on any rigid definition laid down beforehand, but now that we have studied them we think the main feature that justifies separating them is the combination of a left-to-right shunt that is relatively large and a right-to-left shunt that is trivial or absent at rest though sometimes developing on exertion. The right-to-left shunt may gradually become larger so that the condition becomes difficult to distinguish from classical Fallot's tetralogy, but this seems to be unusual.

We think it is better to speak of "ventricular septal defect with pulmonary stenosis" than of 
"acyanotic Fallot's tetralogy." The evidence suggests that over-riding of the aorta is not important in determining the type of shunt. The present cases have, therefore, the same relationship to Fallot's tetralogy that ventricular septal defect has to Eisenmenger's complex, but the change to the cyanotic state is much less certain. The ordinary case of Fallot's tetralogy is one where the stenosis had been severe enough to produce a right-to-left shunt from birth or from an early age.

We have also discussed more shortly eight patients with systolic gradients of less than $35 \mathrm{~mm}$., in most of whom we think there is no organic obstruction. Such gradients cannot by themselves be taken as reliable evidence of stenosis, though in general, if the pulmonary flow is normal, even gradients of about $20 \mathrm{~mm}$. may indicate a real, if slight, organic stenosis. Larger gradients than $40 \mathrm{~mm}$. generally indicate a real organic narrowing, even when the flow is increased, though it may not be enough to produce significant obstruction if the flow can be reduced to normal.

Until ventricular septal defects can be closed with reasonable safety, we do not advise any surgical treatment for patients in this group, as the pulmonary stenosis, though throwing extra work on the right ventricle, reduces the size of the left-to-right shunt and so may prevent the patient developing pulmonary hypertension.

\section{REFERENCES}

Baylis, J. H., Campbell, M., Gilmore, H. R., and Hudson, R. (1955). Guys Hosp. Rep., 104, 114.

Bashour, F., and Winchell, P. (1955). Ann. intern. Med., 42, 1227.

-, Redington, J., and Winchell, P. (1957). Dis. Chest., 31, 423.

Brotmacher, L., and Campbell, M. (1958). Brit. Heart J., $20,97$.

Brown, J. W. (1950). Congenital Heart Disease. 2nd ed., Staples Press, London.

Callahan, J. A., Brandenburg, R. O., and Swan, H. J. C. (1955). Circulation, 12, 994.

Campbell, M. (1954). Brit. Heart J., 16, 273.

-. Deuchar, D., and Brock, R. C. (1954). Brit. med. J., $2,111$.

-, Neill, C., and Suzman, S. (1957). Brit. med. J., 1, 1375.

Contro, S., and Brostoff, P. (1955). Amer. Heart J., 50, 543.

Eldridge, F. L., and Hultgren, H. N. (1955). Amer. Heart J., 49, 838.

Gorlin, R., McMillan, I. K. R., Medd, W. E., Matthews, M. B., and Daley, R. (1955). Amer. J. Med., $18,855$.

Holling, H. E. (1952). Clin. Sci., 11, 283.

Mannheimer, E., Ikkos, D., and Jonsson, B. (1957). Brit. Heart J., 19, 333.

Wood, P., Magidson, O., and Wilson, P. A. O. (1954). Brit. Heart J., 16, 387.

- (1956). Diseases of the Heart and Circulation. 2nd ed. Eyre and Spottiswode, London. 